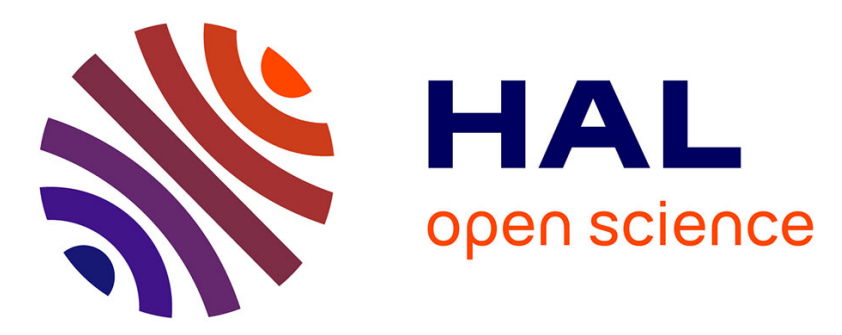

\title{
Developing an Ownership Culture with Employee Share Purchase Plans: Evidence from France
}

Nicolas Aubert

\section{To cite this version:}

Nicolas Aubert. Developing an Ownership Culture with Employee Share Purchase Plans: Evidence from France. German Journal of Human Resource Management Research, 2008, 22 (2), pp.130-151. $10.1177 / 239700220802200203$. halshs-00454021

\section{HAL Id: halshs-00454021 https://shs.hal.science/halshs-00454021}

Submitted on 18 Jan 2016

HAL is a multi-disciplinary open access archive for the deposit and dissemination of scientific research documents, whether they are published or not. The documents may come from teaching and research institutions in France or abroad, or from public or private research centers.
L'archive ouverte pluridisciplinaire HAL, est destinée au dépôt et à la diffusion de documents scientifiques de niveau recherche, publiés ou non, émanant des établissements d'enseignement et de recherche français ou étrangers, des laboratoires publics ou privés. 


\section{Nicolas Aubert ${ }^{*}$}

\section{Developing an ownership culture with Employee share purchase plans: Evidence from France}

Positive effects of employee participation on organizational performance are closely linked to the implementation of a specific corporate culture always referred to as "ownership culture". This issue can be stimulated through employee share purchase plans (ESPP). This article will investigate how to implement a successful ESPP. In order to do so, we review the literature on employees' investment decisions about their employer's shares. We present in another section the data and methodology of the empirical study. We have conducted semi-structured interviews with French experts specialising in ESPP's implementation. We use the content analysis technique to analyse these interviews. Another section is dedicated to presenting the results of the qualitative research. We find that - offering leveraged employee ownership funds - ESPP's general characteristics, - allowing employees to transfer their deferred profit sharing and gain sharing bonuses into the ESPP - discounting the share price, - giving employees payment facilities, - marketing expenses are particularly successful in stimulating employees' investment. In the last section, we discuss and comment on our results.

Keywords: Employee share purchase plan, Employee share ownership, ownership culture.

\footnotetext{
${ }^{*}$ Nicolas Aubert, 1978, Assistant Professor, INSEEC Business School/ECE Lyon 21, rue Alsace Lorraine 69004 LYON (France).

E-mail: naubert@groupeinseec.com.
} 


\section{Introduction}

These days, in France, employee ownership is in the limelight of companies, public authorities and employees themselves these days. Its development is desired and put in place through employee share purchase plans (ESPP). In this article, we investigate how to implement a successful ESPP. When proposing to its employees to buy its shares, a company can pursue several goals. In France, ESPPs often take the form of a Seasoned Equity Offering (SEO) reserved to employees. Employees are offered to buy their company stock at a discounted price. As a consequence, ESPPs are a way to raise equity and a good criterion to assess their success is the percentage of the issued equity subscribed by the employees. However in addition to being a way of corporate financing, an ESPP is a powerful way to present a company's strategy to employees and to seek their approbation. An ESPP can also create or strengthen the corporate culture, for instance after a merger or an acquisition for instance. Shortly after Crédit Agricole and Crédit Lyonnais merged, an ESPP was offered to their employees. In such context, an ESPP can be considered as a corporate referendum whose aim is to maximise the ratio of the number of subscribers to the total number of employees. Firms use several media to convince their employees to buy their shares. Explaining corporate strategy besides the technical aspects of the ESPP is a challenging task. Having defined the two criteria of an ESPP's success (percentage of the issued equity subscribed - percentage of subscribers), we can wonder how they can be achieved. In order to do so, we first describe the specificity of the French legal and social context in the first section. We then review the relevant literature regarding employees' investment decisions about their employer's shares. Until the 2000s, academic literature focused exclusively on how employee ownership affects employees' attitudes at work and company performance. Since then, the uncovering of several corporate scandals caused massive financial losses to employee owners. These events aroused the growing attention of the academic community who got interested in why employees invest in their company's shares. Thanks to this literature, we highlight the motivations that lead employees to participate in an ESPP in a second section. In the third section, we present the data and methodology of the empirical study. We have conducted semi-structured interviews of French experts specialised in ESPP's implementation. They are especially in charge of managing 32 French listed firms' ESPP. Among those firms, a third was multinational corporations part of the CAC 40 index in 2006. We use the content analysis technique to analyze the interviews. The fourth section is dedicated to presenting the results of the qualitative research. The content analysis allows us to identify key factors of an ESPPs' success. Firstly, the leveraged employee ownership funds make it possible for the employees to buy their employer's share by taking a loan. Secondly, the general characteristics of ESPPs are critical, for example the date at which it is implemented. Thirdly, French companies can allow their employees to use their deferred profit-sharing and gainsharing bonuses to buy their stock. Fourthly, discounting the share price stimulates ESPP's participation. Participation can also be stimulated by offering payment facilities. Lastly, the experts lay emphasis on the firm's marketing effort. In the last section, we discuss our results and conclude the paper.

\section{An overview of the French financial participation system}

Employee compensation systems can differ dramatically from one country to another. As far as the European countries are concerned, a European Commission (2003) report highlighted these differences. This latter report identified two financial participation tools: profit-sharing and gainsharing on one hand, employee ownership on another hand. According to it, profitsharing and gainsharing involve giving a bonus to all or part of the staff of an enterprise, generally on the basis of a pre-determined formula. Profit-sharing and gainsharing are 
particularly developed in France, where more than five million employees benefit from them. Profit-sharing is also widespread, largely due to tax reliefs, in the United Kingdom (originally through the "Approved Profit Sharing Plan", and now through the "Share Incentive Plan") and, through normal pay negotiations, hence without any specific incentives, in the Federal Republic of Germany ${ }^{1}$.

As pointed out by Poutsma (2001), French legislation offers a legal framework and generous tax advantages to a variety of financial participation forms. Financial participation in France is rooted in the idea of cooperation between capital and labour introduced by De Gaulle. Since the 1950s, French legislation has continuously developed financial participation in several ways. Gainsharing (intéressement des salariés) was introduced in 1959, the compulsory deferred profit-sharing scheme (participation aux bénéfices) and the company savings plans (Plan d'Epargne Entreprise) in 1967. The compulsory profit-sharing scheme is a characteristic feature of the French participation system. All companies with a minimum workforce of over 50 are required to institute a deferred profit-sharing plan. The compulsory profit-sharing bonuses are blocked for five years. In addition to the company savings plans, French companies can offer ESPPs (Augmentation de capital reserve aux salariés). The difference between the two plans is that the ESPPs are exclusively dedicated to investment in company stock. Employees who invest in ESPPs become shareholders of their own firm. Company savings plans offer more diversified investment opportunities: monetary assets, bonds and stocks. A recent law introduced pension plans (Plan d'Epargne de Retraite Collectif) whose functioning is very similar to the American 401(k) except that they cannot offer company stock as a saving option.

Incentive pay and sponsors' plans contributions are bundled, and framed by several main rules. Providing deferred profit sharing bonuses (primes de participation aux bénéfices) to employees is compulsory for every firm of more than 50 employees whereas gainsharing schemes (accord d'intéressement) are optional. The total amount of profit sharing bonuses is a proportion of the profit. It does not vary among employees as opposed to gainsharing bonuses that can depend on different measures of company or department performance. Another distinction between profit sharing and gainsharing bonuses is that the former must be saved for five years. When the gainsharing bonus is paid, employees are given two choices: (i) get cash and have tax taken; (ii) have the money put into the plans and benefit from taxexemptions. Employees receive a below part rating for their contribution. Amounts invested in ESPP and company savings plans are blocked for a five year period. An early-withdrawal is possible under 11 specific conditions. The most common conditions are employees' lay-off (20\%), divorce (10\%), and bankruptcy (30\%). Finally, aggregate voluntary contributions by each eligible employee may not exceed one fourth of eligible employee's annual gross salary. This limit can also be defined by the firm in the case of an ESPP. It must be said that most of these rules are not specific to the French experience. Similar restrictions and tax shelters are applied in United-States and in the United Kingdom.

\section{Literature review}

Literature on employee ownership investigates the link between employee ownership to organisational and individual outcomes (Kaarsemaker, 2006). It appears that employee ownership's positive outcomes are closely linked to the implementation of a specific organizational culture always referred to as "ownership culture". In companies with an ownership culture, Rosen et al. (2005) emphasise that employees are stimulated to feel, think and act like owners. However from an employee's viewpoint, employee ownership is one

\footnotetext{
${ }^{1}$ We refer the reader to Maillard (2002), Hebestreit (2000) and Wickert (2005) for a more detailed presentation of the French financial participation system.
} 
possible investment among others. To be implemented, ownership culture necessitates employees to become owners of their company often by putting their personal savings at risk. Employees are individual investors whose behaviour is described by economics and finance literature. Before reviewing this literature about employees' investment decisions in their company stock, we should point out to what extent financial economics apply to this specific decision. In fact, financial economists analyse employees' decisions within the field of household finance. Household finance has attracted much recent interest due to the growing interest of individual investors' behaviour. According to Campbell (2006), "household finance asks how households use financial instruments to attain their objectives". He states that "household financial problems have many special features that give household finance its character. Households must plan over long but finite horizons; they have important nontradable assets, notably their human capital; they hold illiquid assets, notably housing; they face constraints on their ability to borrow; and they are subject to complex taxation" (p. 1553). All these features also apply to employee investors' behaviour. Even if household finance still relies on traditional finance theory to understand the behaviour of individual investors, it also has put the emphasis on cognitive phenomena. Consequently, we identified two theoretical streams that help us to understand employees' investment decision regarding their company stock. These are: traditional investment decision making theory assuming agents' rationality on one hand and behavioural finance identifying cognitive biases on the other hand. The literature review allows us to formulate several research propositions.

\section{Investment decision making theory}

This section analyses the concepts of traditional finance theory that are relevant to understand employees' decision to participate in an ESPP. These concepts refer to employees' personal characteristics on one hand, to the ESPPs' features on the other hand.

As far as the employees' personal characteristics are concerned, demographic variables, budget constraint and wealth distribution helps us to describe ESPP's investors' behaviour.

Demographic variables - Individuals and companies' characteristics must be taken into account to predict investment behaviour. As far as the individual variables are concerned, Nobel Prize winners Samuelson, Merton and Modigliani developed life cycle portfolio theory highlighting the importance of age in determining savings and consumption decisions (Merton, 1969 and 1971; Samuelson, 1969; Modigliani and Brumberg, 1954 and 1979). According to life cycle hypothesis, savings increase in the first stage of life and decrease as individuals get closer to retirement. Viceira (2001) and Bodie et al. (1992) showed that demand for risky assets decreases as people get older. Another individual characteristic - that is always difficult to measure empirically - is risk aversion. It is an important component of the optimal portfolio selection models using utility analysis. A proxy of risk aversion can be gender. Indeed, Bernasek and Shwiff (2001) find that women are more reluctant to invest in stock than men. Further more, Hartog et al. (2002) show that risk aversion decreases with income, wealth and education.

Budget constraint - It is always a major determinant of investors' behaviour in economic literature. One can spend more if one earns more. This rule applies to investment in employee ownership according to Degeorge et al. (2004). They showed that salary level was a major determinant of employees' contribution to the France Télécom's first ESPP.

Employees' wealth composition - Following the portfolio theory's arguments, it is worth noting that, by investing in company stock, employees are considering, not only their financial wealth, but rather their overall wealth including their estate property or their human capital. As underlined by Campbell (2006), estate property and human capital are illiquid and not tradable. Studying employee ownership in the 401(k) pension plans, Poterba (2003) suggests that all the components of employees' wealth should be taken into account to predict 
their investment choices. Among these components, Becker (1964) emphasized the central role of human capital. Higher specificity of human capital can discourage investment in company's shares.

Concerning the characteristics of the ESPP itself, profit-sharing bonuses, leveraged funds and discount on the share price are key factors of workers' participation.

Profit-sharing bonuses - As we previously pointed out, budget constraint is always viewed as a key determinant of saving capacity. Blasi and Kruse (2007) mention the possibility of using profit-sharing bonuses as a way to remedy the worker's lack of credit and personal funds to invest in employee ownership. In this view, profit-sharing becomes a vehicle of employee ownership. Employee ownership and profit-sharing are always offered to employees within different plans. Using profit-sharing bonuses as a vehicle of employee ownership simply consists in authorising employees to transfer their savings from their profit-sharing plan to their ESPP.

Leveraged funds - The ability to borrow plays an important role in finance literature. It is another way to relax the employees' budget constraint relying on the so-called leverage effect. Several French multinational corporations take this problem into account by offering employees two ways of participating in an ESPP: a classic offer and a leveraged offer. The classic offer allows employees to invest directly in their company stock. In the leveraged offer, a third-party lender loans money to employees to purchase shares up front at a discount using a line of credit. For each share purchased by the employee, nine additional shares are financed by the third party. At the end of the offering period (5 years), employees repay the lender with a number of shares guaranteed at the outset of the loan, not in cash. The capital invested by the employee can be guaranteed, while the lender hedges in the securities market to protect against risk. As the performance of the investment is pre-calculated, this financial package may be seen as a safer plan than the classic offer.

Discount on the share price - According to Meulbroek (2005) and Ramaswamy (2003). employee ownership comes with a high risk. An obvious way to compensate this risk is to offer employees a discount on the share price. The maximum discount allowed by the French law is $20 \%$ meaning that French employees can buy their company stock at $80 \%$ of its fair market value. According to the French Market Authority, the average discount between 1997 and 2007 is $14,63 \%^{2}$.

Risk of employer's share - Since Markovitz's contribution (Markovitz, 1952), company's characteristics are integrated in portfolio selection analysis through mean and variance of stock returns. With the capital asset pricing model, company's beta coefficient became a worldwide used criterion of investment decision (Sharpe, 1964). Beta coefficient is always considered as a measure of stock's contribution to an overall portfolio risk because it is supposed to capture several aspects of corporate risk like its sensitivity to economic activity, its financial structure, the structure of its costs and the growth rate of its benefits.

Although the variables mentioned so far play a key role in investment decision making, behavioural finance highlighted the existence of several cognitive phenomena we are referring to below.

\section{Behavioural finance}

Behavioural finance can be defined as the study of the influence of psychology on the behaviour of investors. Ritter (2003) considers cognitive psychology as a building block of behavioural finance. Behavioural finance uses models in which some agents are not fully rational, either because of preferences or because of mistaken beliefs ${ }^{3}$.

\footnotetext{
${ }^{2}$ Author's calculation according to the French Market Authority data available online.

${ }^{3}$ Shleifer (2000) provides a more detailed presentation of behavioural finance.
} 
Excessive extrapolation of past returns - Benartzi (2001) shows the existence of "excessive extrapolation" of past returns regarding investment in company stock. Benartzi (2001) argues that employees tend to conclude that abnormally high past performance is representative of future performance, even if stock returns are largely unpredictable. Benartzi shows that employees whose firms experienced a good stock performance are more likely to invest a greater fraction of their wealth in their company stock. His empirical results are highly significant for a preceding period of ten years. Huberman and Sengmueller (2004) and Choi, et al. (2004) confirm that excessive extrapolation also explains new inflows and transfers in the 401( $\mathrm{k})$ plans on shorter preceding period of time. If excessive extrapolation applies to ESPP's participation, firms whose stock price has performed well in the past are more likely to implement a successful ESPP.

Employees' familiarity and loyalty - According to Driscoll et al. (1995), Huberman (2001) and Benartzi (2001), employees tend to invest in their company because they feel familiar with it. As far as employees' loyalty is concerned, Cohen (2008) shows that loyal employees are more willing to invest in their company stock. One can consider familiarity and loyalty as outcomes of ownership culture. Further more, in some countries where individual equity holding is less popular, it is more likely that people are subject to familiarity and loyalty.

Endorsement effect - Benartzi (2001) found that matching contribution in company stock could lead to an "endorsement effect" consisting in employees interpreting their employer's contributions as implicit investment advice. Purcell (2003) and Liang and Weisbenner (2002) confirm this approach by showing that employees put a larger share of their own contributions in company stock when the company's matches are offered in company stock. From this standpoint, the level of the discount offered on the share price can be understood by employees as an implicit investment advice of their employer.

Internal communication - According to Benartzi and Thaler (1999), the way information is displayed can affect individuals' choices. This conclusion put the emphasis on companies' communication policy regarding employee share ownership. Corporate communication policy directed to employees is also identified as a key factor of employees' decision to buy their company stock by Degeorge et al. (2004). For these authors, search costs deterred France Télécom's employees to invest in the ESPP offered in 1997. This cognitive cost includes the time and effort of analysing and understanding the rules of the ESPP. For Degeorge et al. (2004), France Télécom's employees did not select the leveraged fund because they did not understand it.

\section{Research propositions}

We conclude the literature review with the following research propositions. As we previously stated, ESPP's participation can be either measured as the percentage of the issued equity subscribed by the employees or the ratio of the number of subscribers to the total number of employees.

Proposition 1: Age of employees has a negative and curvilinear effect on ESPP's participation.

Proposition 2: Risk aversion affects ESPP's participation negatively.

Proposition 3: Employees’ budget constraint affects negatively ESPP's participation.

Proposition 4: Employees' wealth composition affects ESPP's participation. 
Proposition 5: Allowing employees to invest their profit-sharing bonuses affects positively ESPP's participation.

Proposition 6: Offering leveraged funds affects positively ESPP's participation.

Proposition 7: Discount on share price affects positively ESPP's participation.

Proposition 8: The risk of company stock affects negatively ESPP's participation.

Proposition 9: Past returns affect positively ESPP's participation.

Proposition 10: Employees' familiarity and loyalty affect positively ESPP's participation.

Proposition 11: Internal communication affects positively ESPP's participation.

In the next section, data and methodology of the study are presented.

\section{Data collection and methodology}

The methodology will be exposed in the following sub-sections. We first of all present the studied population and the interview method. We approach finally the basic elements regarding the content analysis.

\section{Population studied}

In order to determine what population to be interviewed, we tried to identify sources of variety. It is critical to start the qualitative research by observing which characteristics can make the content of the interviewees' responses vary. Qualitative research's goal is not representation from a statistical point of view. In fact, the variety of the cases can never be totally captured and the choice of the persons questioned or the number of discussions is a compromise. Conscious of this limit, we looked for content's wealth, his depth and his variety. In the context of our research, we privileged the variety of the experiences of the interviewees. As Mintzberg et al. (1976) point out, a good way to find out how people do things is to ask them. We followed this advice by interviewing ESPP experts. Since the aim of this research is to identify key factors of ESPP's success, we chose to question people supervising these operations. In France, ESPPs are usually managed by banks' subsidiaries. The five most important account keepers in France (Teneurs de compte et conservateurs de parts en épargne salariale) are Natixis asset management, Crédit Agricole, Société Générale asset management, Axa investment manager and BNP Paribas Epargne Entreprise. In June 2007, these five companies managed $77 \%$ of French company based savings according to the French association of financial management (Association française de gestion financière). These companies keep employees' accounts on behalf of their employer. They are in charge of basic operations such as payments, buybacks and transfers. Further more, these enterprises work closely with their clients' human resources and financial departments to design gainsharing, profit-sharing schemes, company savings plans and ESPP. The interviewees are working for one of the above mentioned companies. The department the interviewees work for is divided in four teams. The population interviewed is in charge 32 listed firms belonging to 24 different sectors ${ }^{4}$. A third of these firms are part of the CAC 40 index. The two thirds

\footnotetext{
${ }^{4}$ These sectors are: aerospace, insurance, audiovisual and entertainment, banking, asset management, chemical pharmacy cosmetics, air transport, building construction, defense, food drink and tobacco retail, gas supply, telecommunication equipment retail, clothing and accessories, internet, software, machinery manufacturing, real
} 
remaining are all listed at Euronext France. An adequate sample is determined by the judgment of the researcher, but occurs when further sampling fails to reveal additional categories. Saturation occurs after the eleventh interview. We interviewed 14 ESPP experts. All interviews were done at the interviewees' workplace within a one month period in 2005. As far as the interviewees characteristics are concerned, they are 40 years old and have worked for the company for 13 years on average. Six of the interviewees are women and eight are men. Each one of the fourteen experts manages a portfolio of two or three "large accounts" depending on the size of the client. Table 1 in appendix reports descriptive statistics on the interviewees' characteristics.

\section{Interview method}

We gathered qualitative data using semi-structured interviews. Semi-structured interviews are conducted with a fairly open framework, which allows for focused, conversational, two-way communication. They can be used both to give and receive information. Unlike the questionnaire framework, where detailed questions are formulated ahead of time, semistructured interviewing starts with more general questions or topics. Here, interviewees were asked what leads employees to buy their employer's shares during an ESPP. An interview guide was used. It provided a framework for semi-structured interviewing. In line with Huberman and Miles (2003), all the themes mentioned in this guide were extracted from the literature on employees' investment in their company stock. The interviews lasted between forty-five minutes and one and a half hours.

\section{Analysis}

Berelson (1971) defines content analysis as "a research technique for the objective, systematic, and quantitative description of the manifest content of communication” (p.18). Content analysis is essentially a quantitative method with the core and central tool being its system of categories. Creating these categories requires coding the qualitative data. In order to create the codes, we follow Huberman and Miles (2003)'s deductive procedure. They recommend to develop a start list of codes based on the conceptual framework. We defined this start list thanks to the literature review. Coding the data makes it possible to create categories and sub-categories. Moreover, axial coding allowed us to link different categories (Strauss, 1987). Once the qualitative data are categorised, the relative importance of the categories must be assessed. A simple type of evaluation consists in counting the numbers of occurrences per category assuming there is a relationship between frequency of content and meaning. According to Thiétart (1999), content analysis techniques postulate that the repetition of words or expressions reveals the centres of interest and the preoccupations of the actors. Pellemans (1999) indicates that the quantitative description constitutes one of the essential characteristics of the content analysis. He adds that the small number of individuals questioned does not usually allow data description based on the proportion of individuals having formulated an opinion. Rather than the number of individuals interviewed itself, the total mass of information emitted by them can be the basis of quantification. Following this approach, we classify qualitative data into categories and sub-categories and report their frequencies of appearance.

estate services, oil and gas, pharmaceuticals and medicine manufacturing, motor vehicle accessories manufacturing, beauty and toilet products manufacturing, restaurants and bars, transport services, computer services, communities services, telecommunications. 


\section{Results}

In the following sections, we present categories obtained thanks to experts' interviews coding.

We present the categories and sub-categories highlighted through the content analysis. As mentioned earlier, frequencies of citations are displayed. We get them simply by dividing the number of citations for a given sub-category by the total number of citations in the category. Figure 1 in the appendix shows the relative importance of the main categories. They are reported in ascending order.

The category we named "leveraged funds" is the most frequently cited. It refers to a financial mechanism, which allows the employees to buy nine additional shares for each one purchased through personal contributions. A particular loan makes it possible. The second category is "ESPP's characteristics". It deals specifically with the purchase conditions granted by companies to their workers. Concerning the category called "inflows' origin", it tackles mainly with the money employees can transfer from financial participation schemes like gainsharing and deferred profit-sharing. As far as "company's communication policy", Degeorge et al. (2004) pointed out its critical role during France Télécom's partial privatization. The last two categories emphasise the importance of relaxing employees' budget constraint by offering them "discount on share price" and "payment facilities".

The next sub-sections are dedicated to further analyse the six categories identified. Most of these categories are composed of several sub-categories.

\section{Leveraged funds}

Like many financial tools associated with lever effect, these funds make possible for employees to greatly increase their investment capacity (see Fig. 2). Communication policy about these products is generally summed up by a simple expression: "buy one stock, get ten”. Through this mechanism, a worker can purchase ten shares of his company even if he has not the money to buy all of them. An expert explained the leveraged fund mechanism as follows:

Leveraged funds consist in employees investing one share and getting nine thanks to a credit. Basically, an employee invests one euro and he or she borrows nine Euros.

This quotation associates leveraged funds to the way they are marketed. Indeed, the interviewees' job consists in selling this financial montage to their clients.

According to the interviewees, leveraged funds are especially aimed at stimulating blue collar workers' subscriptions by providing them a way to invest in company's shares even if they do not have enough money to do so. That's why experts underlined employees' characteristics. One of the interviewee stated:

Leveraged funds are appropriate for employees who have a low income [...]. You can buy a lot of shares without spending much because of the lever's multiplication effect.

The employees' characteristic that is referred to is the income viewed as a component of the budget constraint. The experts interviewed suggest that leveraged funds are especially well suited in companies where blue collar workers are numerous. In this type of firms, leveraged funds are likely to maximise the workforce's participation rate. The advantages of leveraged funds must be carefully examined. In fact, they have several drawbacks. Leveraged funds come with a cost. As mentioned by the experts we interviewed, part of his cost is actually 
paid by the employee. Nine out of the ten shares are bought thanks to a loan. The repayment of the loan is made through the withholding of the dividends over the five-year blocking period, the discounts attached to the nine shares and a variable repayment schedule at maturity that is a function of the average share price over five years. Another counterpart is that for the same amount invested, employees' wealth is ten times more concentrated in their company stock. Therefore, leveraged fund is a more risky option in terms of exposure to company stock. Another drawback of this complex financial montage is its cost to the employer. It comes out with a larger equity dilution on the one hand. The operation's engineering is usually outsourced on the other hand.

Of course leveraged funds are a good way to stimulate participation rate but companies generally hesitate a lot before putting them into place because they are very costly to them.

Indeed, according to the interviewee the high cost of offering a leveraged fund to employees often deters firms to use it. The cost of implementing a leveraged fund is all the more high when it is capital guaranteed. Thanks to such an arrangement, employees are insured not to lose a penny of their personal contribution even if the share price decreases under the initial buying price. Such a downside protection is aimed at cancelling employees' exposure to their company stock.

It is not because we are talking of employee ownership that we cannot evoke investment safety. Actually, leveraged funds can also come with a guarantee on the amount invested by the employee. At the end of the five years blocking period, you get your money back even if the stock price has decreased.

This interviewee put the emphasis on the possibility of lowering the risk of investing in company stock thanks to the capital guarantee often associated with leveraged funds. From the employee's point, it consists in becoming an employee owner without bearing any financial risk. This feature explains why leveraged funds are not always considered as a true vehicle of employee ownership.

A disadvantage underlined by the experts is the complexity of this financial montage. Experts we interviewed are especially sensitive to it as it is part of their job to define the ESPP's communication policy. They insisted that employees usually do not understand how leveraged funds work, which often presents an obstacle. For instance, an interviewee addressed the issue of leveraged funds' complexity in the following terms:

How leveraged funds work is really difficult to explain and the average employee do not always understand how these funds work. It is already difficult to understand for us.

This financial montage is so sophisticated that it is also hard to understand for those in charge of selling it. In fact, since each montage must match the customer's demand it is often personalised.

Another expert linked capital guaranteed fund with complexity. According to her, complexity leads to suspicion.

From a strictly financial point of view, with capital guaranteed leveraged funds, employees are certain to get their money back but they don't really understand 
how it is possible to benefit from a stock price increase without suffering from a decrease. Sometimes, they are suspicious.

The complexity associated with leveraged funds is all the more paradoxical that these financial tools were developed to allow the less paid to participate in ESPPs. According to Campbell (2006), the complexity of financial products is an important challenge for household finance. He points out that investment mistakes are not surprising, "given the complexity of households' financial planning problem and the often confusing financial products that are offered to them" (p. 1554). He suggests further that "retail financial innovation is slowed by the cost of advertising and educating households, together with the weakness of patent protection for financial products” (p. 1555). In France, leveraged funds associated with capital guarantee provide an original protection that can stimulate ESPP's participation. Yet, their complexity can deter employees to select them.

\section{ESPP's characteristics}

This second category refers to ESPPs' characteristics (see Fig. 3). The most cited subcategory is “date”. It emphasises the necessity to select carefully the ESPP's date to manage a successful operation according to the criteria we defined earlier. First, periods during which employees make important disbursements must be avoided. The interviewees often cited the end of the year or holidays like in the following quotation. Secondly, it is preferable to organise the ESPP shortly after the profit-sharing and gainsharing bonuses are granted to employees. In doing so, the company can capture these bonuses by allowing its employees to invest them in the ESPP. Selecting an appropriate date can help relaxing employees' budget constraint. The following quotation specifically tackles with this timing aspect:

This year, one of our clients decided to change the schedule of its ESPP in order to increase the success of it. Previously, the ESPP was offered in December. But, at the end of the year, people obviously prefer to spend money in Christmas' presents than in their company stock. This year, they scheduled the ESPP in line with the payment of the profit sharing and gainsharing bonuses. People who did not have enough money to participate in the ESPP invest at least their bonuses. Modifying the ESPP's date had such a critical effect on its success that I cannot understand why they didn't do it before.

From this interviewee's point, re-scheduling the ESPP affects dramatically its success since it offered employees the possibility to transfer their gainsharing and profit-sharing bonuses.

The second most cited sub-category is the ESPP's frequency. Several French listed companies offer ESPPs every two years. As one expert explained it, one firm goes further by offering ESPPs several times a year:

With the [company X], we have an ESPP quarterly.

Such a strategy cannot be separated from a continuous effort to promote employee ownership. These repeated ESPPs create an opportunity effect by proposing employees to invest in their company stock at a discounted price. Employees also benefit from tax incentives. It should be mentioned that these advantages have a counterpart. In France, ESPP's participants cannot sell out their shares for five years. Other phenomena linked to the ESPP's frequency are the "endowment effect" (Thaler, 1980) and what we would refer to as the "learning effect". The first one implies that people place a higher value on objects they own relative to objects they do not. Endowment is likely to affect employees who 
participated in a previous ESPP by leading them to increase their investment in an asset they already own their company stock. Secondly, employees who already participate in an ESPP are more familiar with it. Thanks to their previous knowledge of previous ESPP, their "search cost" - the cost of analysing the information provided by the company - is lowered by their previous experience of ESPP's participation.

Among the ESPP's characteristics to be taken into account a posteriori, the interviewees mentioned the participation rate as a signal of the operation's success:

We can say an ESPP worked very well if 50\% of the workforce participated in it. Participation rates are usually higher during an Initial Public Offering. As far as our clients are concerned, participation rates are between $33 \%$ and $50 \%$ of the workforce.

This interviewee gave us an idea of what can be considered as a successful ESPP. She considered Initial Public Offering (IPO) as very specific events. Every time an IPO or a Seasoned Equity Offering (SEO) is implemented, the French law requires the general meeting of shareholders to vote on offering an ESPP. If an ESPP and an IPO or a SEO are offered at the same time, ESPP is part of a larger effort to sell shares.

Frequent ESPPs can bring about negative effects if they lead to a high concentration of employees' wealth in employee ownership. This financial risk must never be neglected as it can damage employees' work attitudes. The sub-category entitled employer's contributions regards financial conditions offered to the employees. As we will see in a following section, financial contributions usually take the form of a discount on the share price. However employers can also offer matching contribution or free shares to their workers under the conditions specified by the French Law. Here is how an interviewee referred to these additional contributions:

In addition to the discount offered on the share price, employers frequently grant their employees other financial incentives such as matching contributions or free shares.

The maximum discount authorised by law is $20 \%$. But the way it is marketed can change from one firm to another. That's why this interviewee mentioned it. For instance, some companies prefer to say: "buy four shares, get one free" or "spend 40 Euros, we offer 10". Of course, it is similar to getting a $20 \%$ discount. Here, it is interesting that the same marketing tools are used to sell shares to employees as in retailing.

The sub-category referred to as "complexity" indicates that the subscription methods can sometimes be difficult to understand for employees who are not familiar with the stock market mechanisms. This sub-category put the emphasis on how important pedagogy can be to implement a successful ESPP. One expert evoked a specific example to highlight this point in the following quotation:

Two years ago, a client of our own organized an ESPP. It turned out to be a failure according to the participation rate. Afterwards, it appeared that many employees did not understand the operation's mechanisms.

For most French employees, purchasing their employer's shares is often their first experience with the financial market. Degeorge et al. (2004) reported the French reluctance to hold shares as opposed to American behaviour. These latter underlined the limited experience with direct equity-holding of French individual investors. In fact, the perceived complexity of the 
stock market may also weaken ESPP's participation. However recent data on French household stock ownership tend to show that employee ownership is the main component of individual stock ownership (TNS Sofres NYSE Euronext survey, 2007). According to this feature, French people would consider company stock as a specific asset category. This view is consistent with Benartzi and Thaler (2001) who state: "It appears that the mental accounting of these investments involves putting the company stock into its own category separate from other equities” (Benartzi and Thaler, 2001, p. 595).

\section{Inflows' origins}

In addition to the money coming from their personal savings, employees willing to invest in their company stock can be given other ways to do so. Of course, financial participation does not only consist in employee ownership. Gainsharing and profit-sharing bonuses encounter a large success worldwide. In the context of an ESPP, French companies have the possibility to allow their employees to use their profit-sharing and gainsharing bonuses to buy their shares. This possibility is usually restricted to the bonuses granted during the current year. Another condition is that these bonuses must already be invested in the company savings plan (Plan d'Epargne Entreprise). Figure 4 shows that the "profit-sharing bonuses" sub-category is the most frequently cited one. This reveals the importance of employers' financial contribution granted to their workers. The French law requires the deferred profit-sharing bonuses to be blocked for five years. Further more, these bonuses cannot benefit from any employer's matching contribution. However profit-sharing bonuses, if invested in an ESPP, can benefit from a discount on employer's shares. In fact, if an employee keeps his profit-sharing bonus blocked, he does not benefit from any extra money. Conversely, if he decides to transfer this amount into the ESPP, he gets at least a discount on his company stock. Gainsharing bonuses do not entail the same restrictions since they can be withdrawn at any time and they can benefit from matching contributions outside the ESPP.

Instead of investing their profit-sharing bonus in a risk free mutual fund without getting any extra money, employees prefer to get a discount by participating in the ESPP. The choice is really put this way: Either you put your money in secure asset but you don't get anything more or you invest in your company and benefit from a $20 \%$ discount. The second one sounds more appealing for most employees.

The interviewee suggests that employees tend to adopt a rational behaviour by maximising financial advantages. According to him, employees tend to look for additional employer's contribution whatever the form they take. From the employer's point, authorising employees to redirect their profit-sharing bonuses in the ESPP makes profit-sharing a gradual vehicle of employee ownership consistently with Kruse and Blasi (2007).

Moreover, when employees are granted the right to redirect their bonuses in the ESPP, they endure a lowered saving cost. In fact, the money employees can invest in the ESPP was already saved elsewhere. The following quotation refers to this phenomenon:

Giving employees the right to invest bonuses in the ESPP is a good incentive. People get their bonus and they invest it in the ESPP. It is not as if they had to spend some extra money. [...] Employees do not really have the feeling to invest because their profit-sharing bonus is frozen five years anyway. They don't feel they are doing an addition saving effort. 
Profit-sharing bonuses relax employees' saving effort. It looks as if employees consider them as employer's money. From a corporate finance point of view, this mechanism is a way to transform a cost into equity that is employees' compensation into new shares.

By allowing the redirection of financial participation bonuses into the ESPP, employers stimulate their employees' saving potential and ultimately ESPP's participation.

\section{Company's communication policy}

This category put the emphasis on ESPPs organizers' marketing effort. Its impact during France Télécom's partial privatisation has already been underlined by Degeorge et al. (2004). Companies' management can consider an ESPP as a great opportunity to communicate directly with employees on corporate strategy and investment projects. According to the interviewees, an adequate communication policy must ally several supports such as the intranet, stock price simulators, films, posters, CD ROMs and information meetings. In order to overcome the complexity hurdle mentioned earlier, pedagogy is critical. Specialised consulting companies are usually in charge of implementing appropriate communication policy preceding an ESPP. The largest companies also rely on a network of relay people. These are ordinary employees in charge of promoting the ESPP throughout the firms' divisions by explaining it to their colleagues. One of the interviewees especially raised several of these issues:

The communication campaign usually starts six months before the ESPP. Employees must be aware they can buy their employer's shares and get a discount on the share price. Communication media are particularly important. Targeted employees have to be determined. Such a perimeter is not always easy to define for a large corporation with many subsidiaries. As far as the multinational corporations are concerned, different legal systems have to be taken into account. Communication campaign will vary according to the context. Communication documents handed out to employees have to follow specific rules defined by the financial market authorities. In order to implement an adequate communication campaign, marketing and HRM departments work together. It takes a long time to select the appropriate words.

The interviewee highlighted several aspects of communication policy. In order to be effective, the communication policy must start months before the ESPP. Another step is to define the targets in terms of employees, subsidiaries or countries. Once the objectives are defined, the communication policy can be implemented by taking into account different contextual variables. But communication policy can come with frequently neglected drawbacks. In fact, communication is often delegated to internal hierarchy, which could result in a harmful situation. On one hand, subordinates can feel like they have no choice but participating in the ESPP. On another hand, managers can find themselves in an ambiguous situation. As managers, their role is to adopt corporate strategy and to translate it into operational instructions. However when it comes to convince their subordinates to invest their personal money in the firm, managers can potentially interfere with their colleagues' private life. Moreover, managers may consider they are required to agree with corporate strategy and therefore, to participate in the ESPP. Those are some of the reasons why communication policy must be implemented cautiously otherwise it can sometimes result in bad effects on employees' work attitudes. 


\section{Discount on the share price}

Figure 5 reports the relative importance of sub-categories regarding the category "discount on the share's price". Financial economists generally regard discounts on stock price as the way to compensate financial risk associated to employee ownership. For instance, Meulbroek (2005) and Ramaswamy (2003) followed this point trying to evaluate the cost of investing in employee ownership. In France, the maximum legal threshold of the discount is $20 \%$ of the share price. According to Meulbroek (2005), this proportion cannot compensate the cost of employee's risk exposure. Nevertheless, experts consider the discount as the main incentive to participate in an ESPP. From the point of one of them:

The majority of employees are above all motivated to invest in the ESPP because of the discount.

Benartzi (2001) highlighted how behavioural factors can affect employee's investment behaviour. He referred to one of them as "endorsement" effect. According to this latter, employees tend to interpret their employer's financial contribution as implicit advice to buy company stock. Employees would consider the management team holds private information about future returns on company's share.

\section{Payment facilities}

Figure 6 reports the relative importance of sub-categories regarding the category "payment facilities". This section refers to different ways of payment available to employees. They are aimed at helping employees to buy their employer's shares during an ESPP. According to an experts' point of view:

Giving employees payment facilities is a good incentive to participate in the ESPP. For instance, the company can propose direct monthly withdrawals on employees' bank accounts in order to pay their participation in the ESPP.

Among these facilities, employees can allow their employer to withdraw the money directly from their personal bank account. Those withdrawals can be done in several instalments at no extra cost or at a lowered interest rate. If employees opt for this possibility they are in fact issuing a credit. Such a cheap credit is made possible thanks to an arrangement between the employer and a subcontracting bank. Of course, this sort of arrangement is costly for the employer. But, like the leveraged funds, it can increase the amount invested in the ESPP by facilitating the participation of employees with the lowest available income.

\section{Discussion and conclusion}

The goal of the present article was to bring about a better understanding of what determines the success of an ESPP. The success of such an operation can be assessed through several criteria according to corporate strategy. In fact, a company may want to stimulate workforce's participation rate or to maximise the total amount sold to employees. Since an ESPP can be seen as an internal opinion poll on corporate strategy, it is critical to manage it appropriately by using all the means available. The specificity of this internal opinion poll is that it is observable by outside investors. The failure of an ESPP can be interpreted as a bad signal. Indeed, corporate finance literature regards insiders' ownership as a signal of corporate value. The insiders are generally considered as better informed than outside investors. This better knowledge could be translated in terms of investment in the firm. This point was particularly underlined by Leland and Pyle (1977). Accordingly, employees' 
participation in the ESPP would reveal firm value and a failure would show employees do not support corporate strategy and would display their bad attitudes. Paradoxically, oversubscription of the total equity offered to employees cannot always be perceived as a success. It means workers did not get the total amount they ask which can lead to frustrations. Further more, it can also emphasise the lack of knowledge managers have about their employees' commitment to the company.

This field study research put the emphasis on several aspects of ESPP. It pointed out that ESPPs are a powerful mean to develop employee ownership. Several experts interviewed insisted on this aspect. In this view, offering an ESPP to workers translates corporate culture regarding employee ownership into facts. Research on the theme of employee ownership highlighted the key role of management philosophical commitment to financial participation and of extrinsic incentives. Our results are in accordance with this analysis. By giving their employees financial incentives, companies can show their employees how much they are committed to develop employee ownership through an ESPP. Several categories tackle with the importance of granting employees financial incentives to participate in the ESPP. Among those incentives, experts identify leveraged funds, discount on share price, inflows' origin and payments facilities as determinants of employees' participation. Whereas some of these categories can be analysed as bonuses (namely discount on share or free credit), most of them are actually aimed at relaxing employees' budget constraint. These results are in line with our propositions 5, 6 and 7 which relate to savings incentives. The aim of - allowing investment of profit-sharing bonuses (proposition 5), - offering leveraged funds (proposition 6) and giving discount on company's shares (proposition 7) is clearly to increase employees' saving capacity. Whatever the combination selected, all these mechanisms are costly to the firm. As for the experts interviewed, leveraged funds are the most powerful way to stimulate employees' participation. However the impact of this tool should not be overestimated. Although it has been especially designed to increase participation rate by allowing the lower paid employees to buy their company stock, simply understanding how it works can be challenging. Even if the leveraged fund was the most valuable investment during France Télécom's partial privatisation, employees disregarded it. Degeorge, et al. (2004) concluded this complicated offering scheme deterred employees to invest through it. In addition to this complexity, investing in leveraged fund results in increasing employees' risk exposure. For the same amount invested, it multiplies holding in company's shares. Financial risk bore by employees must not be underestimated. Excessive risk exposure can lead to bad outcomes on work attitudes according to Blasi and Kruse (2006). Another proposition that is emphasized by our paper relates to internal communication. The interviews show the many different forms communication can take to promote ESPP's participation. This paper underlined how complexity of sophisticated financial tools like leveraged fund can deter employees to invest in their company stock. This search cost is very similar to the fixed cost of participating in savings plan underlined by Campbell (2006). He remarks that even negligible fixed cost can deter households' investment in equity. A good communication policy is an appropriate way to decrease the search cost employees must pay to analyse and understand their employer's offer. But assessing this cognitive cost is all the more challenging that it is different for every employee. Decreasing this fixed cost should be the aim of an ESPP's communication policy anyway.

Concerning the other propositions, they refer to employees' and firms' characteristics. Although they are always considered as critical determinants of investment decision by the literature dealing with portfolio selection, the interviewees did not mention them explicitly. Nevertheless, some propositions are associated to other categories. Leveraged fund, profitsharing and discount on share price provide means to relax budget constraint (proposition 3). Capital guarantee cancels the risk of investing in company stock (proposition 8). The 
interviewees did not mention some other employees' characteristics such as age (proportion 1), risk aversion (proposition 2), employees' wealth composition (proposition 4), loyalty and familiarity (proposition 10). This is doubtlessly because the interviewees never interact with employees contrarily to HRM people. They insisted on what strategy can be implemented to stimulate ESPP's participation (leveraged funds, profit-sharing bonuses, discount, communication policy) instead of putting the emphasis on what is considered as given or not modifiable (employees' age, risk aversion, wealth composition, familiarity, company's risk and past returns).

One limit of this research calls for future investigation. It is due to the nature of the data. Although the interviewees are in charge of several French firms' ESPPs, they all work for the same account keeper. Future research can investigate which ESPPs practices are attributable to the account keepers' influence. As this sector is very competitive in France, we suppose these practices do not vary dramatically from an account keeper to another. In addition to this investigation, we would suggest a quantitative test of our research propositions. Such a test could focus on the numerous ESPPs offered in France.

\section{References}

Becker Gary (1964): Human Capital: a Theoretical and Empirical Analysis, with Special Reference to Education. National Bureau of Economic Research (ed.), New York.

Benartzi, Shlomo (2001): Excessive Extrapolation and the Allocation of 401(k) Accounts to Company Stock. In: The Journal of Finance, 56, 1747-1764.

Benartzi Shlomo / Thaler Richard (1999): Risk Aversion or Myopia? Choices in Repeated Gambles and Retirement Investments. In: Management Science, 45, 364-381.

Benartzi Shlomo / Thaler Richard (2001): Naive Diversification Strategies in Defined Contribution Saving Plans. In: American Economic Review, 91, 79-98.

Berelson Bernard (1971): Content Analysis in Communication Research. Hafner (ed.), New York.

Bernasek Alexandra / Shwiff Stephanie (2001): Gender, Risk, and Retirement. In : Journal of Economic Issues, 35, 345-356.

Blasi Joseph / Kruse Douglas (2006): Risk: Is It Economic Democracy or Just Another Risk For Workers? Employee Attitudes Towards Risk-sharing and Financial Participation in Company Rewards. Russell Sage/NBER conference in New York City. Russell Sage and Rockefeller Foundations, New York.

Bodie Zvi / Merton Robert / Samuelson Paul (1992): Labor Supply Flexibility and Portfolio Choice in a Life Cycle Model. In: Journal of Economic Dynamics and Control, 427-449.

Campbell John (2006): Household Finance. In: The Journal of Finance, 51, 4, 1553-1604.

Choi James / Laibson David / Madrian Brigitte / Metrick Andrew (2004): Employees' Investment Decisions About Company Stock. In: Pension Design Structure: New lessons from behavioral finance, O. S. a. U. Mitchell, Stephen P. (ed.). Oxford University Press, 121-136.

Cohen Lauren (forthcoming): Loyalty Based Portfolio. In: Review of Financial Studies.

Degeorge Francois / Jenter Dirk / Moel Alberto / Tufano Peter (2004): Selling Company Shares to Reluctant Employees: France Telecom's Experience. In: Journal of Financial Economics, 71, 169-202.

Driscoll K. / Malcolm J. / Sirull M. / Slotter P. (1995): 1995 Gallup Survey of Defined Contribution Plan Participants, John Hancock Financial Services. 
European Commission (2003): Report of the High Level Group of Independent Experts, on Cross-border Obstacles to Financial Participation of Employees for Companies Having a Transnational Dimension.

Hartog Joop / Ferrer-I-Carbonnel Ada / Jonker Nicole (2002): Linking Measured Risk Aversion to Individual Characteristics. In: Kyklos, 55, 3-26.

Hebestreit Carsten (2000): Arbeitnehmer-Aktienbeteiligung und Unternehmenswert. München und Mering: Hampp Verlag.

Huberman Gur (2001): Familiarity Breeds Investment. In: Review of Financial Studies, 14, 659-680.

Kaarsemaker Eric (2006): Employee Ownership and Human Resource Management: a Theoretical and Empirical Treatise with a Digression on the Dutch Context. Doctoral Dissertation. Radboud University Nijmegen, Nijmegen, the Netherlands.

Miles Matthew / Huberman Michael (1994): Qualitative Data Analysis: An Expanded Sourcebook. Sage (ed.).

Leland Hayne and Pyle David (1977): Informational Asymmetries, Financial Structure, and Financial Intermediation. In: The Journal of Finance, 32, 371-387.

Maillard Paul (2002): Intéressement, Participation, Actionnariat Salarié. Dalloz.

Markovitz Harry (1952): Portfolio Selection. In: The Journal of Finance, 7, 77-91.

Merton Robert (1969): Lifetime Portfolio Selection under Uncertainty: the Continuous-time Case. In: Review of Economics and Statistics, 51, 247-257.

Merton Robert (1971): Optimum Consumption and Portfolio Rules in a Continuous-time Model. In: Journal of Economic Theory, 3, 373-413.

Meulbroek Lisa (2005): Company Stock in Pension Plans: How Costly is it? In: Journal of Law and Economics, 48, 443-474.

Mintzberg Henry / Raisinghani Duru / Théorêt Andre (1976): The Structure of 'Unstructured' Decision Processes. In: Administrative Science Quarterly, 21, 246-276.

Modigliani Franco / Brumberg Richard (1954): Utility Analysis and the Consumption Function: an Interpretation of Cross-section Data. In: Post Keynesian Economics. K. Kurihara (ed.). Rutgers University Press, New Brunswick.

Modigliani Franco / Brumberg Richard (1979): Utility Analysis and Aggregate Consumption Functions: an Attempt of Integration. In: Collected Papers of Franco Modigliani, Vol. 2. Abel A. (ed.). MIT Press, Cambridge.

Pellemans Paul (1999) : Recherche Qualitative en Marketing. DeBoeck Université, Paris.

Poutsma Erik (2001): Recent Trends in Employee Financial Participation in the European Union. Luxembourg: Office for the Official Publications of the European Union.

Poterba James (2003): Employer Stock and 401(k) Plans. In: American Economic Review, 93, 398-404.

Purcell Patrick (2003): Employer Stock in Retirement Plans: Investment Risk and Retirement Security. Report for US Congress. Congressional Research Service.

Ramaswamy Krishna (2003): Company Stock and Pension Plan Diversification. In: Olivia Mitchell, and Kent Smetters (ed.). In: The Pension Challenge: Risk Transfers and Retirement Income Security. Oxford University Press, Philadelphia.

Ritter Jay (2003): Behavioral Finance. In: Pacific-Basin Finance Journal, 11, 429-437.

Rosen Corey / Case John / Staubus Martin (2005): Equity: Why Employee Ownership is Good for Business? Harvard Business School Press, Boston.

Samuelson Paul (1969): Lifetime Portfolio Selection by Dynamic Stochastic Programming. In: Review of Economics and Statistics, 51, 239-246.

Sharpe William (1964): Capital Asset Prices: a Theory of Market Equilibrium under Conditions of Risk. In: The Jounal of Finance, 19, 425-442. 
Shleifer Andrei (2000): Inefficient Markets: an Introduction to Behavioral Finance. Clarendon Lectures. Oxford University Press, New York.

Strauss Anselm (1987): Qualitative Analysis for Social Scientists, Cambridge University Press, New York.

Thaler Richard (1980): Toward a Positive Theory of Consumer Choice. In: Journal of Economic Behavior and Organization, 39-60.

Thiétart Raymond-Alain (1999) : Méthodes de Recherche en Management, Dunod, Paris.

TNS and NYSE Euronext (2007) : Étude TNS Sofres pour NYSE Euronext sur les Valeurs Mobilières Détenues par les Français en 2007.

Viceira Luis (2001): Optimal Portfolio Choice for Long-horizon Investors with Nontradable Labor Income. In: The Journal of Finance, 56, 433-470.

Wickert Heiko (2005): Monetäre Erfolgsbeteiligungssysteme in Großbritannien und Frankreich. München und Mering. Hampp Verlag.

\section{Appendices}

Table 1: Interviewees - descriptive statistics

\begin{tabular}{lcccc}
\hline Interviewee & Tenure & Age & Gender & Accounts \\
\hline 1 & 4 & 30 & W & 2 \\
\hline 2 & 15 & 45 & W & 3 \\
\hline 3 & 2 & 28 & W & 3 \\
\hline 4 & 10 & 37 & W & 3 \\
\hline 5 & 15 & 40 & W & 3 \\
\hline 6 & 20 & 50 & W & 2 \\
\hline 7 & 3 & 30 & M & 1 \\
\hline 8 & 17 & 45 & M & 1 \\
\hline 9 & 10 & 38 & M & 2 \\
\hline 10 & 20 & 49 & M & 2 \\
\hline 11 & 5 & 32 & M & 3 \\
\hline 12 & 17 & 42 & M & 2 \\
\hline 13 & 10 & 38 & M & 3 \\
\hline 14 & 35 & 58 & M & 2 \\
\hline Total & - & - & - & 32 \\
\hline Mean & 13,07 & 40,14 & - & 2,29 \\
\hline Standard deviation & 8,51 & 8,38 & - & 0,70 \\
\hline $\begin{array}{l}\text { Note: the “Accounts" column refers to the number of firms the interviewee is in } \\
\text { charge of. }\end{array}$ & & & & \\
\hline
\end{tabular}


Figure 1: Categories

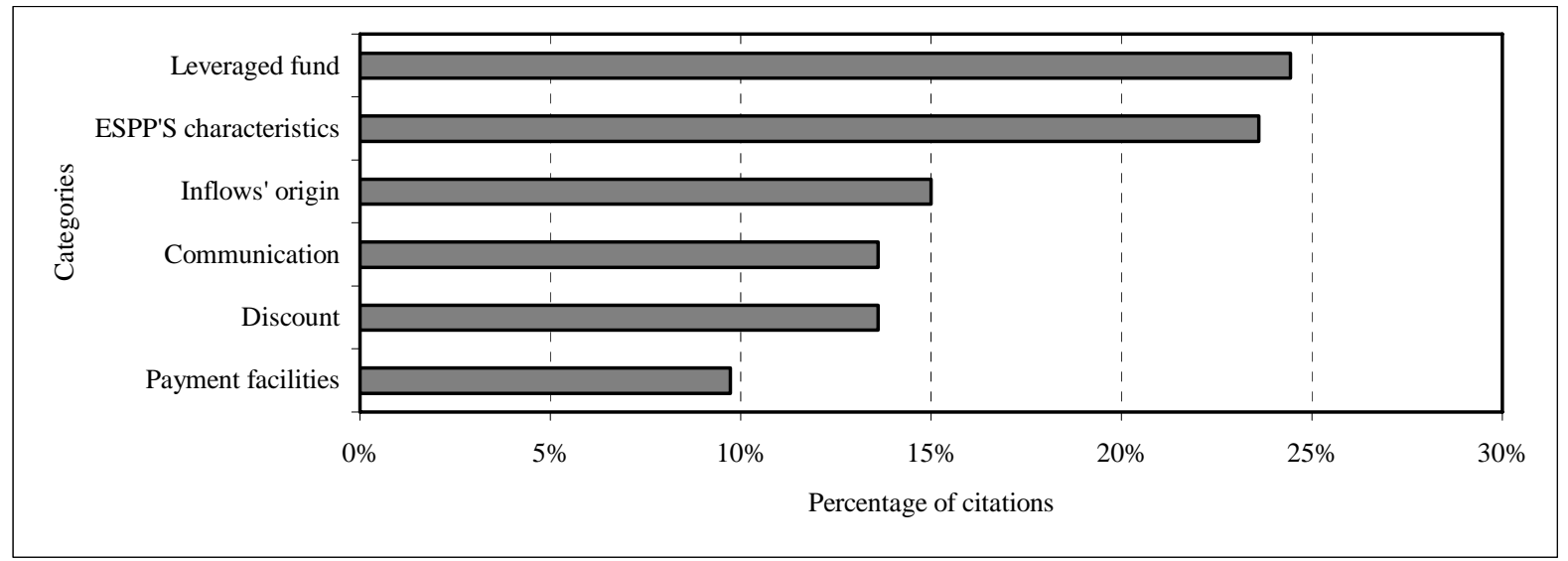

Figure 2: Sub-category - ESPP's characteristics

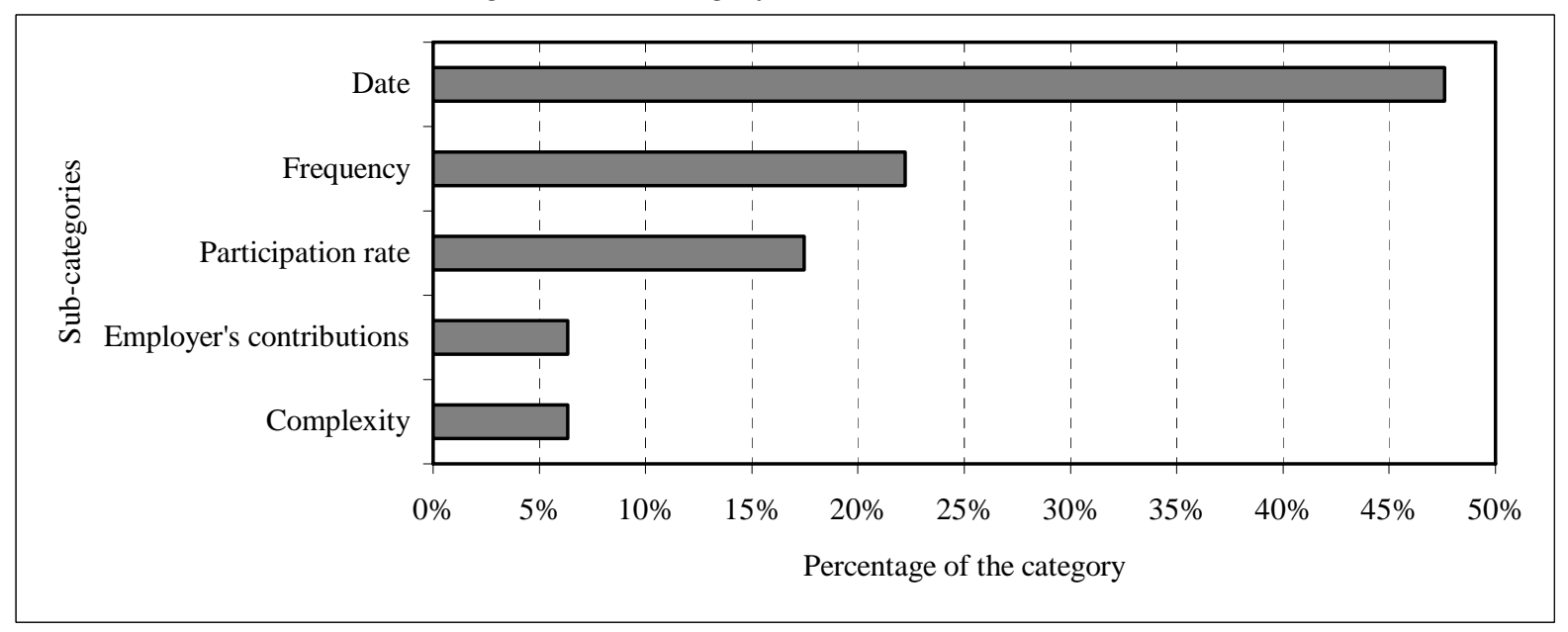

Figure 3: Sub-category - leveraged funds

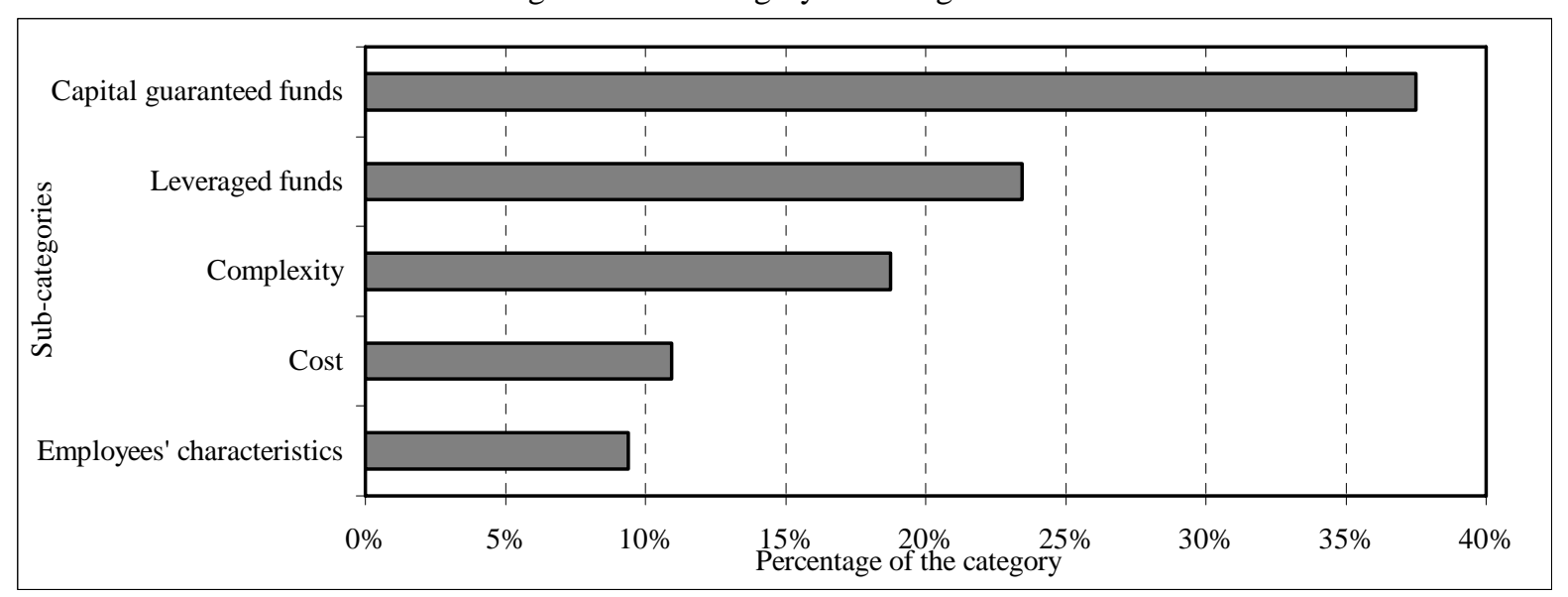


Figure 4: Sub-category - inflows’ origins

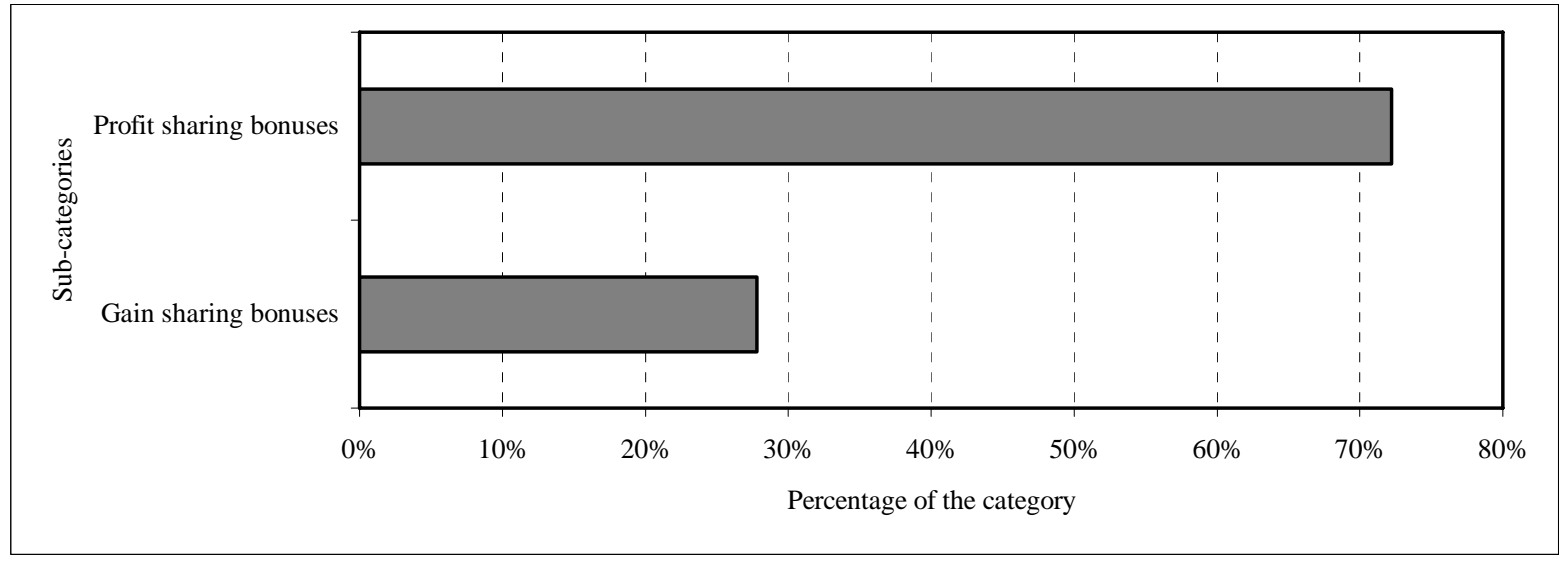

Figure 5: Sub-category - discount on the share's price

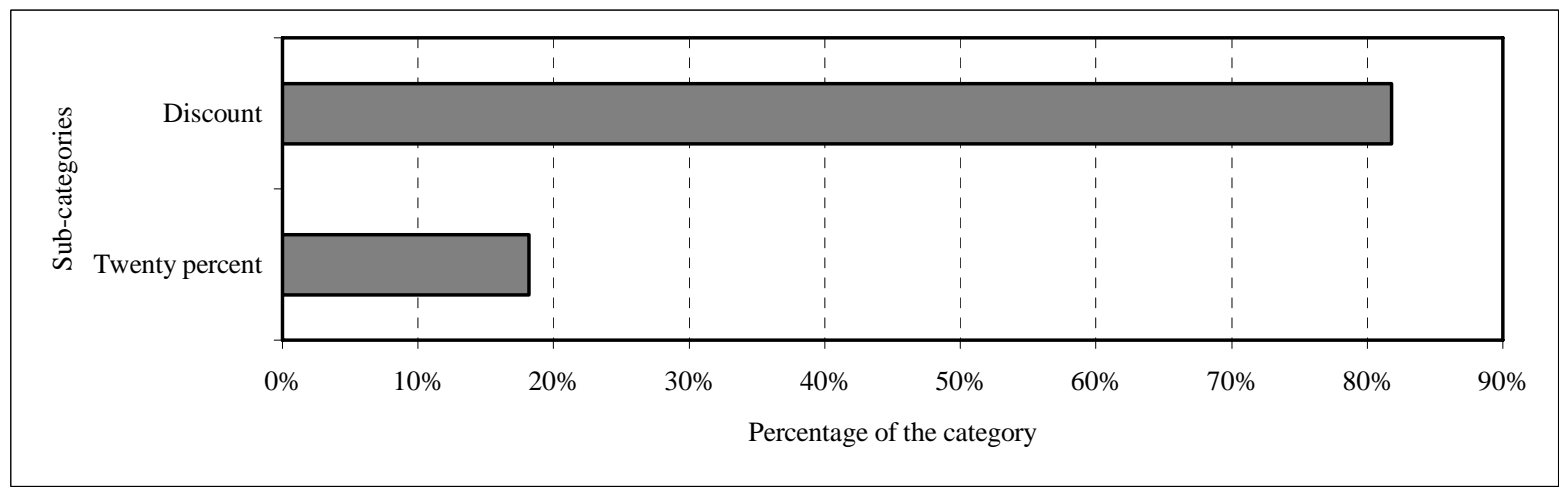

Figure 6: Sub-category - Payment’s facilities

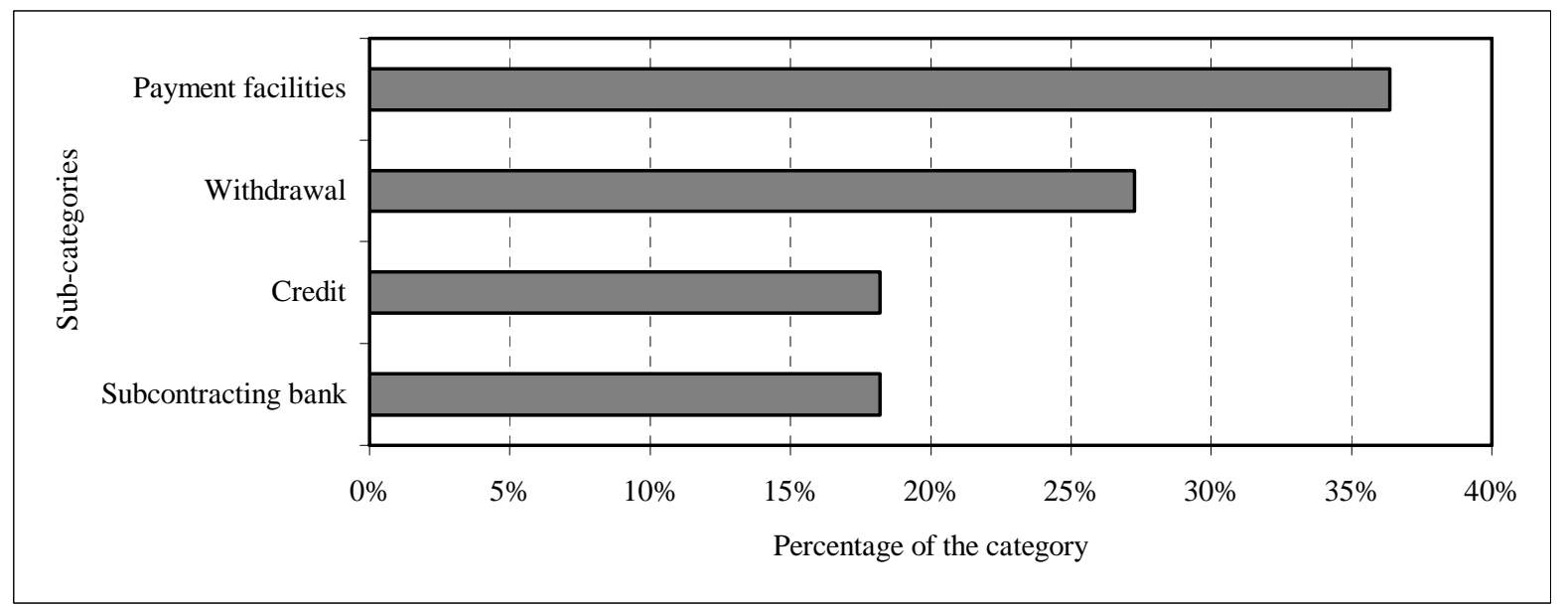

